\title{
A DNA Segment Controlling Metal-Regulated Expression of the Drosophila melanogaster Metallothionein Gene Mtn
}

\author{
EDWARD OTTO, ${ }^{1 *}$ JAMES M. ALLEN, ${ }^{2}$ JULIE E. YOUNG,${ }^{1}$ RICHARD D. PALMITER, ${ }^{2}$ \\ AND GUSTAVO MARONI ${ }^{1}$ \\ Department of Biology and Curriculum in Genetics, University of North Carolina, Chapel Hill, North Carolina 27514, ${ }^{1}$ \\ and Howard Hughes Medical Institute Laboratory, Department of Biochemistry, University of Washington, \\ Seattle, Washington $98195^{2}$
}

Received 15 December 1986/Accepted 9 February 1987

\begin{abstract}
Cloned fragments of DNA including the Drosophila melanogaster metallothionein gene Mtn and different amounts of $5^{\prime}$ flanking sequences were introduced into flies by P-element-mediated germ line transformation. Comparison of RNA levels in different transformants revealed that metal-regulated and tissue-specific expression of Mtn requires no more than 373 base pairs upstream of the initiation site of transcription. Transformants having an additional, transcribed copy of $M t n$ could tolerate increased concentrations of cadmium, indicating that $M t n$ expression is directly related to this phenotype. In separate experiments, these $D$. melanogaster promoter sequences were fused to the coding sequences of the herpes simplex virus thymidine kinase (TK) gene. After transfection of this fusion into baby hamster kidney cells, increases in TK activity and accumulation of TK RNA were inducible by metals. A series of $5^{\prime}$ and $3^{\prime}$ deletions showed that $D$. melanogaster sequences from -130 to -6 were sufficient to confer metal-regulated expression to the TK gene. The function of the $D$. melanogaster metallothionein promoter in mammalian cells indicates that the mechanism controlling metal regulation is evolutionarily conserved.
\end{abstract}

Metallothioneins (MTs) are small, cysteine-rich proteins that bind heavy metals. Although their complete physiological role is not yet known, they appear to protect cells against toxic metals and may be involved in the homeostatic regulation of essential elements such as zinc and copper (6, $8,10,20)$. In mammals, there are multiple MT genes, and exposure of cells or animals to heavy metals results in a rapid increase in their transcription $(2,5,7,12)$. Several of these genes have been cloned and found to retain their ability for metal-regulated expression following transfer into heterologous mammalian cells $(7,11,18,24)$.

Metal induction of mouse MT-1 gene transcription is controlled by metal-regulatory elements, 12-base-pair DNA segments that are repeated four times within the MT-1 promoter (28); similar metal-regulatory elements are present in other mammalian MT promoters (28). In Drosophila melanogaster, the MT gene Mtn is associated with DNA segments resembling mammalian metal-regulatory elements; seven such segments occur 300 base pairs or less upstream of the transcriptional initiation site, and each is identical to the consensus mammalian metal-regulatory element in at least 9 of 12 bases (15). To test whether the region containing these segments was responsible for metal-regulated expression of Mtn and whether this region would function in a heterologous mammalian system, we introduced portions of Mtn into flies and into baby hamster kidney cells. We show here that metal-regulated and tissue-specific expression of $M t n$ in D. melanogaster germ line transformants does not require more than 373 base pairs upstream of the transcriptional initiation site and that this region controls metalregulated expression in hamster cells. In addition, we show that a shorter region extending from -130 to -6 is sufficient for metal regulation in these cells.

\footnotetext{
* Corresponding author.
}

\section{MATERIALS AND METHODS}

Vector constructions. A plasmid with $\mathrm{P}\left[-373 \mathrm{MtnL} 1 \mathrm{ry}^{+}\right]$ was constructed by ligating the 3.5-kilobase (kb) EcoRI fragment containing the $D$. melanogaster MT structural gene into the EcoRI site of pPSX $\Delta 1$ (obtained from J. Posakony, University of California, San Diego). This plasmid was then digested with BamHI and ligated to a fragment (L1) derived from the mouse interspersed repeat L1Md (17). The resulting plasmid contained a transposon that was a precursor for all of those shown in Fig. 1A. For P $\left[-3900 M\right.$ tnL1ry ${ }^{+}$, linear fragments obtained from a partial EcoRI digestion of this plasmid were ligated to a 3.5-kb EcoRI fragment that contained adjacent upstream sequences of Mtn; restriction endonuclease analysis was used to identify clones having this fragment inserted in such a way as to restore the natural organization of Mtn. For $\mathrm{P}\left[+54 \mathrm{MtnL} 1 r y^{+}\right]$, these linear molecules were digested with $S t u I$ and the products were fractionated on a $0.7 \%$ agarose gel. Molecules that contained the same DNA as those in the linear fragment but lacked a 427-base-pair EcoRI-StuI fragment from the 5' end of Mtn were extracted from the gel, treated with Klenow polymerase, and religated. The final step in the construction of each transposon was the insertion of an 8.1-kb Sall fragment, containing $r y^{+}$, into the $X h o I$ site within pPSX $\Delta 1$. Construction of $\mathrm{P}\left[-373 \mathrm{Mtnry}^{+}\right]$was the same as that of $\mathrm{P}[-373 \mathrm{Mtn}$ Llry ${ }^{+}$, except that L1 was not added.

$3^{\prime}$ deletions of the Mtn promoter were constructed by BAL 31 exonuclease digestion from the EcoRV site of a genomic subclone, pDm131 (15). This DNA was then digested with SmaI, ligated to yield circular plasmids, and subcloned. Mtn promoter fragments were obtained from each of these plasmids by digestion with EcoRI, treatment with Klenow polymerase, and then digestion with BamHI. To create the MtnTK fusions, these fragments were used to replace the normal thymidine kinase (TK) promoter, be- 


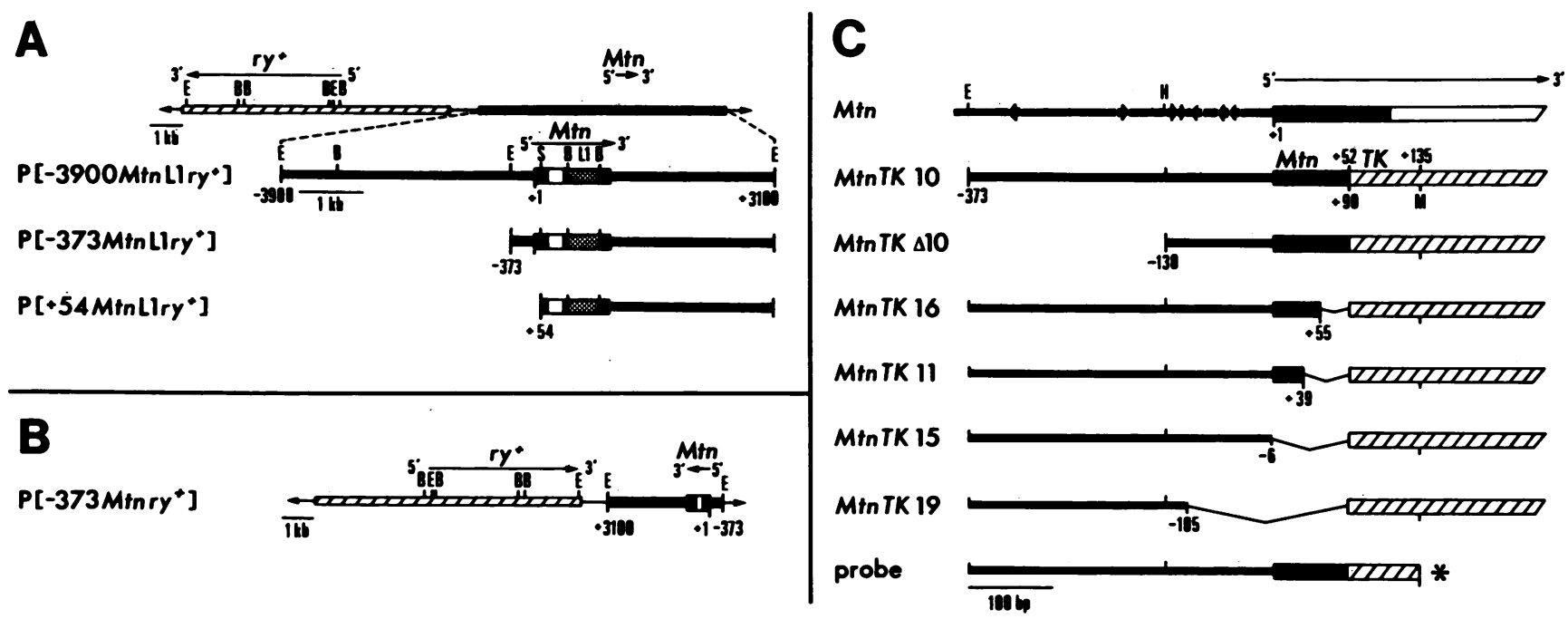

FIG. 1. Mtn vectors used in germ line transformation and transfection experiments. (A) Transposons carrying a D. melanogaster MT gene tagged with L1 DNA. Top line, restriction map of a transposon that contained one of the three different Mtn fragments shown below it.

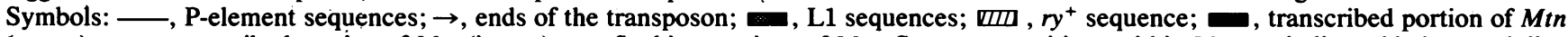
(exons); $\square$, transcribed portion of Mtn (intron); - , flanking portions of Mtn. Sequence positions within Mtn are indicated below each line and are relative to the transcriptional initiation site at +1 . Restriction sites: B, BamHI; E, EcoRI; S, StuI. (B) Transposon carrying a normal D. melanogaster MT gene. (C) Deletion mutations used in transfection experiments. Top line, wild-type restriction map of the $5^{\prime}$ region of Mtn. Regions of Mtn are represented as in panel A. Arrows represent 12-mers in which at least nine bases correspond to the consensus sequence identified as the metal-regulatory element in mammals $(15,28)$. Below, deletion mutations created by fusing portions of $M t n$ to the TK structural gene. $\mathrm{mm}$, TK sequences. The sizes of Mtn fragments were estimated from a polyacrylamide gel. Positions within $M t n$ are indicated below each line, and positions within $T K$ are above; numbers are relative to their respective transcriptional initiation sites at +1 . The end-labeled $\left(^{*}\right)$ probe that was used in S1 analysis (Fig. 3B) is shown on the bottom line. Restriction site: M, MluI.

tween the $P v u I I$ and $B g I I I$ sites, of a plasmid containing the PvuII-HindIII fragment spanning the herpes simplex virus TK gene (type 1) (27). The 5' deletion MtnTK $\Delta 10$ was created by subcloning the HindIII fusion fragment from MtnTK 10 into pUC18.

D. melanogaster transformation and hamster cell transfection. Germ line transformation was carried out by the method of Rubin and Spradling (22). $A d h^{f n 6} c n$; $r y^{506} \mathrm{em}-$ bryos were injected with mixtures containing a test plasmid at $300 \mu \mathrm{g} / \mathrm{ml}$ and $\mathrm{p} \pi 25.7 \mathrm{wc}(9)$ at $100 \mu \mathrm{g} / \mathrm{ml}$. G1 transformants were crossed to flies of the host strain, and temporary lines were maintained by selecting $r y^{+}$progeny. The linkage group for the transposon in each line was determined by scoring, after the appropriate genetic crosses, $r y^{+}$segregation with respect to the balancers $\mathrm{CyO}$ (for the second chromosome) and $M K R S$ (for the third). Permanent lines (a

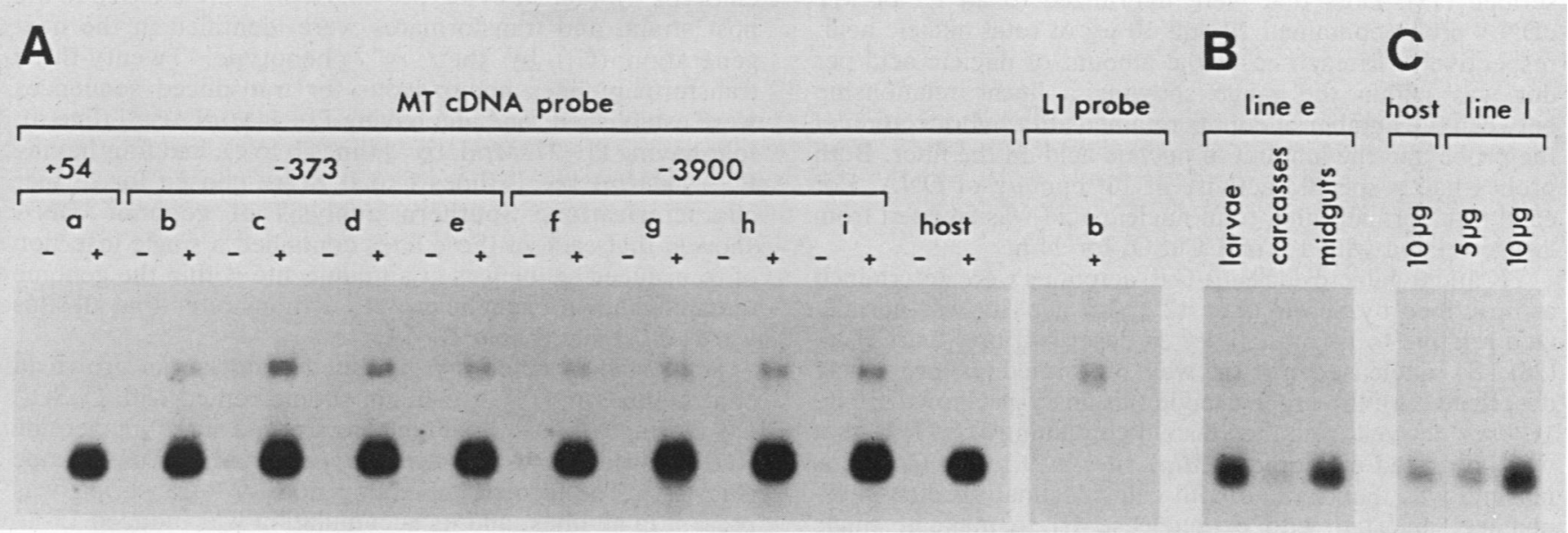

FIG. 2. Expression of transduced Mtn in germ line transformants. Autoradiographs of blots of total nucleic acid that was electrophoresed on denaturing agarose gels. (A) Each lane contained $5.0 \mu \mathrm{g}$ of nucleic acid that was isolated from the host strain or from transformants containing $\mathrm{P}\left[+54 \mathrm{MtnL} \mathrm{Lry}^{+}\right]$(line a), $\mathrm{P}\left[-373 \mathrm{MtnL} 1 r y^{+}\right]$(lines b to e), or $\mathrm{P}\left[-3900 \mathrm{MtnL} 1 r y^{+}\right]$(lines $\mathrm{f}$ to $\mathrm{i}$ ). For each line, larvae were uninduced $(-)$ or treated with $5.0 \mathrm{mM} \mathrm{CuSO}_{4}$ for $48 \mathrm{~h} \mathrm{(+)}$. Blots were hybridized to a D. melanogaster MT cDNA probe (13) or to an L1 probe. (B) Each lane contained nucleic acid from four larvae or from the dissected organs of four larvae. All larvae were from line $e$ and were treated with $1.0 \mathrm{mM} \mathrm{CuSO}_{4}$ for $24 \mathrm{~h}$. The blot was hybridized to the $D$. melanogaster MT cDNA probe. Carcasses were all organs that remained after the midgut was removed. Similar results were obtained for lines b to $d$ (data not shown). (C) Nucleic acid was isolated from larvae of the host strain or transformants having a transduced copy of a normal MT gene. All larvae were treated with $5.0 \mathrm{mM} \mathrm{CuSO}$ for $24 \mathrm{~h}$. The amount of total nucleic acid in each lane is indicated. The blot was hybridized to the same probe used in panel $B$. 
TABLE 1. MT RNA levels in D. melanogaster germ line transformants

\begin{tabular}{|c|c|c|c|c|c|}
\hline Probe & Transposon injected & Line & $\begin{array}{l}\text { Chromosome } \\
\text { of insertion }\end{array}$ & Mean $\mathrm{cpm}^{a} \pm \mathrm{SE}$ & $\begin{array}{l}\text { cpm relative } \\
\text { to host }\end{array}$ \\
\hline \multirow[t]{10}{*}{ L1 } & $\mathrm{P}\left[+54 M \operatorname{tn} \mathrm{L}_{1} r y^{+}\right]$ & a & 3 & $12.4 \pm 0.7$ & \\
\hline & $\mathrm{P}\left[-373 M \operatorname{mL} \mathrm{L} 1 r y^{+}\right]$ & b & 2 & $96.8 \pm 8.2$ & \\
\hline & & c & 2 & $176.8 \pm 9.9$ & \\
\hline & & d & 3 & $124.3 \pm 8.7$ & \\
\hline & & e & 3 & $102.2 \pm 3.6$ & \\
\hline & $\mathrm{P}\left[-3900 \mathrm{MtnL} 1 r y^{+}\right]$ & $\mathrm{f}$ & 2 & $96.7 \pm 9.9$ & \\
\hline & & $\mathbf{g}$ & 3 & $119.4 \pm 7.4$ & \\
\hline & & $\mathrm{h}$ & 3 & $80.1 \pm 3.3$ & \\
\hline & & $\mathrm{i}$ & 3 & $105.5 \pm 5.8$ & \\
\hline & None & Host & & $7.8 \pm 0.3$ & \\
\hline \multirow[t]{5}{*}{ MT cDNA } & $\mathrm{P}\left[-373\right.$ Mtnry $\left.{ }^{+}\right]$ & j & 2 & $692.7 \pm 66.4$ & 1.6 \\
\hline & & $\mathrm{k}$ & 2 & $782.7 \pm 41.6$ & 1.8 \\
\hline & & 1 & 3 & $809.0 \pm 80.8$ & 1.9 \\
\hline & & $\mathrm{m}$ & 3 & $678.6 \pm 24.2$ & 1.6 \\
\hline & None & Host & & $430.3 \pm 22.5$ & 1.0 \\
\hline
\end{tabular}

${ }^{a}$ For each line, mean of three determinations.

to $\mathrm{m}$ ) that were homozygous for the chromosome containing the transposon were then obtained by using the same balancers. See reference 14 for descriptions of balancers and mutations.

Baby hamster kidney $\mathrm{TK}^{-}$cells were transfected as described by Searle et al. (25).

Molecular analyses. Isolation of total nucleic acid from $D$. melanogaster larvae and Northern blot analyses were performed as previously described (13). The relative expression of endogenous genes and transduced MT genes in lines b to $i$ was determined by scintillation counting of portions of the blot that corresponded to individual bands on the autoradiograph (Fig. 2A).

Dot hybridizations were performed as previously described (13). Dots that were hybridized to an L1 or MT cDNA probe contained 20 and $10 \mu \mathrm{g}$ of total nucleic acid, respectively. In each case, the amount of nucleic acid per dot was within the range showing a linear relationship between the number of counts retained after hybridization of the probe and the amount of nucleic acid on the filter. Both probes had a specific activity of $10^{8} \mathrm{cpm} / \mu \mathrm{g}$ of DNA. For each transformant line, total nucleic acid was isolated from larvae treated with $1.0 \mathrm{mM} \mathrm{CuSO}_{4}$ for $24 \mathrm{~h}$.

TK and $\beta$-galactosidase ( $\beta$-Gal) activities were determined as described by Searle et al. (25); TK activity was normalized relative to $\beta-\mathrm{Gal}$ activity as described by Stuart et al. (28). S1 nuclease analysis was performed as previously described (24); the probe used in this analysis (shown in Fig. 1C) was derived from the plasmid containing MtnTK 10 that was linearized at a unique MluI site, at +135 of $T K$. This plasmid was then treated with calf intestinal alkaline phosphatase, digested with exonuclease III to make it single stranded, and end-labeled with $\left[\gamma^{32} \mathrm{P}\right] \mathrm{ATP}$ by using polynucleotide kinase.

\section{RESULTS AND DISCUSSION}

D. melanogaster transformants carrying a MT gene tagged with a fragment of heterologous DNA. Germ line transformation vectors were constructed that contained, within a de- fective P-element, genomic restriction fragments derived from the $D$. melanogaster MT clone $\lambda \mathrm{Dm} 13$ (15) and an $8.1-\mathrm{kb}$ rosy ${ }^{+}\left(r y^{+}\right)$fragment (4). Three different Mtn fragments, extending from $-3900,-373$, and +54 to +3100 , were used to create transposons $\mathrm{P}\left[-3900 \mathrm{MtnL} 1 r y^{+}\right]$, $\mathrm{P}\left[-373 M \operatorname{tnL} 1 r y^{+}\right]$, and $\mathrm{P}\left[+54 M \operatorname{tnL} 1 r y^{+}\right]$, respectively (Fig. 1A). To help distinguish the expression of transduced MT genes from that of endogenous ones, a 500-base-pair fragment of mouse DNA, L1, was inserted in exon 2 of Mtn. Probes derived from $\mathrm{L} 1$ failed to hybridize to genomic DNA from the host strain (data not shown); thus, this probe was used to determine directly the level of expression of transduced genes.

Each vector was coinjected with $\mathrm{p} \pi 25.7 \mathrm{wc}$ into $r y^{506}$ host embryos with the $\mathbf{M}$ cytotype. Survivors were crossed to the host strain, and transformants were identified in the next generation $\left(G_{1}\right)$ by their $r y^{+}$phenotype. Twenty-three transformant lines homozygous for transduced sequences were established; one line having $\mathrm{P}\left[+54 M \operatorname{tnL} 1 r y^{+}\right]$(line a), four having $\mathrm{P}\left[-373 \mathrm{MtnL} \mathrm{L}^{+} \mathrm{y}^{+}\right]$(lines $\mathrm{b}$ to $\mathrm{e}$ ), and four having $\mathrm{P}\left[-3900\right.$ MtnL1ry $\left.{ }^{+}\right]$, (lines $\mathrm{f}$ to i), were chosen for further characterization. Southern analysis of genomic DNA showed that each of these lines contained a single insertion of transduced sequences at a unique site within the genome (data not shown); genetic crosses demonstrated that all sites were autosomal (Table 1).

Total nucleic acid was extracted from larvae grown in control medium (16) or medium supplemented with $\mathrm{CuSO}_{4}$. On Northern blots, a 400-nucleotide and a 900 -nucleotide RNA hybridized to a $D$. melanogaster MT cDNA probe (Fig. 2A). The former, the endogenous MT transcript, was present in all lines, and its accumulation was induced 15- to 20 -fold by metal treatment, as expected (13). The latter, present in lines $b$ to $i$, was the transcript of the transduced genes; it was larger than the endogenous transcript by the expected amount and comigrated with the only RNA that hybridized to an $\mathrm{L} 1$ probe. It was also inducible, but the amount produced by the transduced genes was only a small fraction (10 to $15 \%$ ) of the endogenous MT RNA. We were unable to detect the larger RNA in line a or the host strain. 
TABLE 2. Tolerance of $D$. melanogaster germ line transformants to cadmium chloride

\begin{tabular}{|c|c|c|c|}
\hline Transposon injected & Line & $\begin{array}{l}\text { Mean } L^{2} C_{50}^{a} \\
(\mu \mathrm{M}) \pm \mathrm{SE}\end{array}$ & $\begin{array}{l}\text { Relative } \\
\text { LC }_{50}\end{array}$ \\
\hline $\begin{array}{l}\mathrm{P}\left[+54 M t n L 1 r y^{+}\right]^{b} \\
\mathrm{P}\left[-373 M t n r y^{+}\right]^{b}\end{array}$ & $\begin{array}{l}a \\
1\end{array}$ & $\begin{array}{l}14.6 \pm 1.0 \\
24.3 \pm 1.5\end{array}$ & $\begin{array}{l}1.0 \\
1.7\end{array}$ \\
\hline $\begin{array}{l}\mathrm{P}\left[-373 M \operatorname{mi} \mathrm{L}_{1 r y^{+}}\right]^{c} \\
\mathrm{P}\left[-373 \mathrm{M} t n r y^{+}\right]^{c}\end{array}$ & $\begin{array}{l}\mathrm{e} \\
1 \\
\mathrm{~m}\end{array}$ & $\begin{array}{l}31.0 \pm 1.0 \\
46.0 \pm 4.0 \\
48.0 \pm 4.0\end{array}$ & $\begin{array}{l}1.0 \\
1.5 \\
1.5\end{array}$ \\
\hline
\end{tabular}

${ }^{a} \mathrm{LC}_{50}$ values represent the concentration of $\mathrm{CdCl}_{2}$ that would be expected to yield $50 \%$ survival and were estimated by interpolation from the relative viability values described below.

${ }^{b}$ Average $\mathrm{LC}_{50}$ values were estimated from the results of three independent experiments. In each experiment, 10 male and 10 female flies of each line (a or 1) laid eggs in a culture vial for $72 \mathrm{~h}$ and were then discarded (all flies were of the same age). Vials contained either control medium (16) or medium supplemented with various concentrations of $\mathrm{CdCl}_{2}(20,40,80$, or $160 \mu \mathrm{M})$. For each concentration, relative viability was calculated as the proportion of individuals (progeny) that reached pupariation under that treatment compared with individuals reared on unsupplemented food.

c Average $\mathrm{LC}_{50}$ values were estimated from the results of two independent experiments. These experiments were performed as described in footnote $b$, except that 30 first-instar larvae (from control medium), instead of the progeny of 10 pairs of flies, were cultured in each vial. All calculations were based on the numbers of these larvae that reached pupariation (16).

Dissections of metal-treated larvae showed that the transduced genes were expressed primarily within the midgut cells, as were the endogenous genes (Fig. 2B). We measured the level of expression of transduced genes by hybridization of an L1 probe to dot blots of total nucleic acid from treated larvae (Table 1). The amount of hybridization in lines $\mathrm{f}$ to $\mathrm{i}$ $(-3900)$, as a group was not greater than that in lines b to $\mathrm{e}$ $(-373)$. The low level of background hybridization in line a was similar to the host level; therefore, it appears that this transduced gene was not expressed. These results demonstrate that (i) sequences from -373 to +54 are required for the expression of $\mathrm{Mtn}$; (ii) the presence of an additional 3.5 $\mathrm{kb}$ of $5^{\prime}$ flanking sequence does not increase this expression; and (iii) despite small differences observed among lines, the level of expression of functional transduced genes in each line is much lower than that of the endogenous genes.

$D$. melanogaster transformants carrying a transduced, normal MT gene. To determine whether the low level of expression of transduced genes was due to the presence of the heterologous L1 sequence, a normal MT gene was introduced into flies. A segment of $M t n$ similar to the one in $\mathrm{P}\left[-373 \mathrm{Mtn} \mathrm{L}_{1 r y}{ }^{+}\right]$, but lacking the $\mathrm{L} 1$ segment, was used to create the transposon $P\left[-373\right.$ Mtnry $\left.^{+}\right]$(Fig. 1B). Four lines $(j$ to $\mathrm{m}$ ) homozygous for the chromosome containing this transposon were analyzed. Southern blots showed that each line contained a single insertion of the transposon at a unique site (data not shown), and genetic analyses revealed that each site was on an autosome (Table 1). Thus, each line had four copies of $\mathrm{Mtn}$; if the transduced genes were functioning normally, the levels of MT RNA in these lines should be twice as high as those in the host strain.

MT RNA levels in the host strain and in these transformants were compared by hybridization of the MT cDNA probe to total nucleic acid from treated larvae. Northern blots showed that some transformants appeared to have approximately twice as much of the 400-nucleotide MT transcript as the host strain (Fig. 2C). Dot hybridizations revealed that the transduced genes were expressed at a level equivalent to 60 to $90 \%$ of the endogenous gene (Table 1). Differences in the expression of transduced genes are attributed to the influence of chromosomal position and have been observed for other genes $(1,23,26)$. These results suggest that the low level of expression observed for genes carrying the L1 segment is due either to interference of this segment with transcription or, more likely, to instability of L1-MT RNA. Thus it appears that the region of Mtn from -373 to +3100 contains most, if not all, of the sequences required for normal expression of this gene. These limits are consistent with those suggested by a tandem duplication of this gene, $D p(3 ; 3) M t n^{H 22}$; larvae with this duplication had an extra copy of sequences from -228 to +2000 and contained twice as much MT RNA as strains with a single copy (20).

Transformants carrying this transposon were 1.5 - to 1.7 fold more resistant to cadmium chloride than were transformants carrying $\mathrm{P}\left[+54 \mathrm{Mtn \textrm {L }} 1 r y^{+}\right]$or $\mathrm{P}\left[-37^{2} \mathrm{Mtn \textrm {L }} 1 r y^{+}\right]$ (Table 2). These results indicate that these transduced genes are functional and that $\mathrm{Mtn}$ is directly responsible for resistance to cadmium.
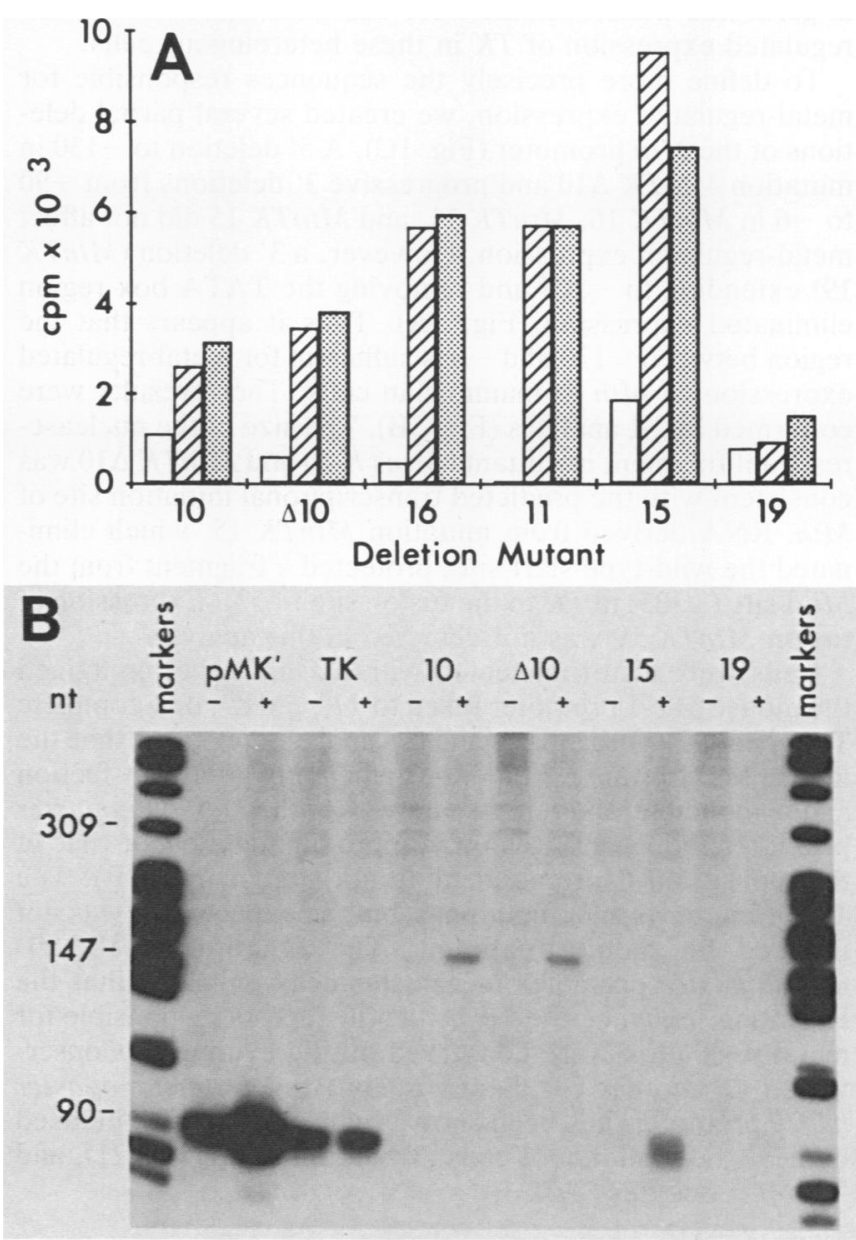

FIG. 3. Relative expression of deletion mutations after transfection into baby hamster kidney cells. (A) For each mutation, we assayed TK activity in untreated cells $(\square)$ and in cells treated with $0.1 \mathrm{mM} \mathrm{ZnCl}{ }_{2}$ for $12 \mathrm{~h}(\mathrm{Em}$, experiments). TK values are relative to $\beta-G a l$ activities. Uninduced cells containing the mutation MtnTK 11 had a $\beta-G a l$ activity level that was below background; therefore, no TK value is given. (B) Autoradiograph showing the S1 nuclease-resistant products of a digestion of hybrids between the probe shown in Fig. 1C and RNA that was isolated from transfected cells. Cells were grown for $8 \mathrm{~h}$ in the absence $(-)$ or presence $(+)$ of $0.1 \mathrm{mM} \mathrm{ZnCl}_{2}$. Markers are end-labeled HpaII fragments of pBR322. 
Function of the Mtn promoter in transfected hamster cells. The $5^{\prime}$ flanking region required for $M t n$ expression in germ line transformants had been previously shown to contain DNA sequences that are strikingly similar to those responsible for metal regulation of the mouse MT-1 gene $(15,28)$. To determine whether the function of this region was conserved, we examined the activity of the $D$. melanogaster promoter in mammalian cells. Mtn sequences from -373 to +90 were fused to a viral TK gene to create MtnTK 10 (Fig. $1 C)$. The plasmid with this fusion and a reference plasmid containing the mouse MT-1 promoter fused to a $\beta-\mathrm{Gal}$ gene,

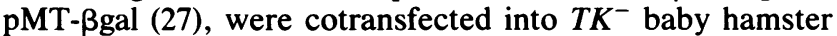
kidney cells. TK and $\beta-G a l$ activities in cells grown in the presence or absence of metal were assayed; $\beta$-Gal served as a control for variation in transfection efficiency and thus provided an internal standard for comparison of Mtn promoter activity in each experiment. TK activity was inducible in cells containing $M \operatorname{tn} T K 10$ (Fig. 3A); therefore, the same 5 ' flanking sequences that were required for Mtn expression in germ line transformants were sufficient to control metalregulated expression of $T K$ in these heterologous cells.

To define more precisely the sequences responsible for metal-regulated expression, we created several partial deletions of the Mtn promoter (Fig. 1C). A 5' deletion to -130 in mutation $M t n T K \Delta 10$ and progressive $3^{\prime}$ deletions from +90 to -6 in MtnTK 16, MtnTK 11, and MtnTK 15 did not affect metal-regulated expression. However, a $3^{\prime}$ deletion (MtnTK 19) extending to -105 and removing the TATA box region eliminated expression (Fig. 3A). Thus it appears that the region between -130 and -6 is sufficient for metal-regulated expression of $\mathrm{Mtn}$ in mammalian cells. These results were confirmed by $\mathrm{S} 1$ analysis (Fig. 3B). The size of the nucleaseresistant fragment in mutants $M t n T K 10$ and $M t n T K \Delta 10$ was consistent with the predicted transcriptional initiation site of Mtn. RNA derived from mutation MtnTK 15 , which eliminated the wild-type start site, protected a fragment from the $M l u I$ site $(+135)$ in $T K$ to the fusion site $(+52)$. Expression of fusion MtnTK 19 was not detected in this analysis.

Cells were also transfected with plasmids that contained the mouse MT-1 promoter fused to $T K$, $\mathrm{pMK}^{\prime}$, or a complete TK gene (27). TK assays and $S 1$ analysis revealed that the mouse MT-1 promoter functions efficiently after transfection and is inducible; the relative activity of the $D$. melanogaster promoter, however, was only approximately $5 \%$ of that of the mouse MT-1 promoter (data not shown; Fig. 3B). The TK promoter is also functional, but, as expected, it was not induced by metal treatment. The function of the $D$. melanogaster promoter in hamster cells indicates that the cis-acting sequences and trans-acting factors responsible for metal regulation were conserved during evolution. Conservation of another regulatory region, the $D$. melanogaster hsp70 promoter, has been shown by its ability to be induced by heat shock in mouse cells $(3)$, monkey cells $(19,21)$, and Xenopus oocytes (29).

\section{ACKNOWLEDGMENTS}

We thank D. Kubai and L. Kalfayan for their comments on the manuscript. We are also grateful to A. Gutierrez for technical assistance with germ line transformation and to $S$. Whitfield for the artwork.

This work was supported by Public Health Service grants ES02654 to G.M. and HD-09172 to R.D.P. from the National Institutes of Health.

\section{LITERATURE CITED}

1. Bourouis, M., and G. Richards. 1985. Remote regulatory sequences of the Drosophila glue gene $s g s 3$ as revealed by
P-element transformation. Cell 40:349-357.

2. Brinster, R. L., H. Y. Chen, R. Warren, A. Sarthy, and R. D. Palmiter. 1982. Regulation of metalliothionein-thymidine kinase fusion plasmids injected into mouse eggs. Nature (London) 296:39-42.

3. Corces, V., A. Pellicer, R. Axel, and M. Meselson. 1981. Integration, transcription, and control of a Drosophila heat shock gene in mouse cells. Proc. Natl. Acad. Sci. USA 78:7038-7042.

4. Coté, B., W. Bender, D. Curtis, and A. Chovnick. 1986. Molecular mapping of the rosy locus in Drosophila melanogaster. Genetics 112:769-783.

5. Durnam, D. M., and R. D. Palmiter. 1981. Transcriptional regulation of the mouse metallothionein-1 gene by heavy metals. J. Biol. Chem. 256:5712-5716.

6. Hamer, D. H. 1986. Metallothionein. Annu. Rev. Biochem. 55:913-951.

7. Hamer, D. H., and M. Walling. 1982. Regulation in vivo of a cloned mammalian gene: cadmium induces the transcription of a mouse metallothionein gene in SV40 vectors. J. Mol. Appl. Genet. 1:273-288.

8. Kagi, J. H. R., and M. Nordberg (ed.). 1979. Metallothionein. Birkhauser Verlag, Basel.

9. Karess, R. E., and G. M. Rubin. 1984. Analysis of P transposable element functions in Drosophila. Cell 38:135-146.

10. Karin, M. 1985. Metallothioneins: proteins in search of a function. Cell 41:9-10.

11. Karin, M., G. Cathala, and M. C. Nguyen-Huu. 1983. Expression and regulation of a human metallothionein gene carried on an autonomously replicating shuttle vector. Proc. Natl. Acad. Sci. USA 80:4040-4044.

12. Karin, M., A. Haslinger, H. Holtgreve, R. I. Richards, P. Krauter, H. M. Westphal, and M. Beato. 1984. Characterization of DNA sequences through which cadmium and glucocorticoid hormones induce human metallothionein- $\mathrm{II}_{\mathrm{A}}$ gene. Nature (London) 308:513-520.

13. Lastowski-Perry, D., E. Otto, and G. Maroni. 1985. Nucleotide sequence and expression of a Drosophila metallothionein. J. Biol. Chem. 260:1527-1530.

14. Lindsley, D. L., and E. H. Grell. 1968. Genetic variations of Drosophila melanogaster. Carnegie Institution of Washington Publication 627. Carnegie Institution, Washington, D.C.

15. Maroni, G., E. Otto, and D. Lastowski-Perry. 1986. Molecular and cytogenetic characterization of a metallothionein gene of Drosophila. Genetics 112:493-504.

16. Maroni, G., and D. Watson. 1985. Uptake and binding of cadmium, copper and zinc by Drosophila melanogaster larvae. Insect Biochem. 15:55-63.

17. Martin, S. L., C. F. Voliva, F. H. Burton, M. H. Edgell, and C. A. Hutchison. 1984. A large interspersed repeat found in mouse DNA contains a long open reading frame that evolves as if it encodes a protein. Proc. Natl. Acad. Sci. USA 81: 2308-2312.

18. Mayo, K. E., R. Warren, and R. D. Palmiter. 1982. The mouse metallothionein-I gene is transcriptionally regulated by cadmium following transfection into human or mouse cells. Cell 29:99-108.

19. Mirault, M., R. Southgate, and E. Delwart. 1982. Regulation of heat-shock genes: a DNA sequence upstream of Drosophila hsp70 genes is essential for their induction in monkey cells. EMBO J. 1:1279-1285.

20. Otto, E., J. E. Young, and G. Maroni. 1986. Structure and expression of a tandem duplication of the Drosophila metallothionein gene. Proc. Natl. Acad. Sci. USA 83:6025-6029.

21. Pelham, H. R. B. 1982. A regulatory upstream promoter element in the Drosophila hsp70 heat-shock gene. Cell 30:517-528.

22. Rubin, G. M., and A. C. Spradling. 1982. Genetic transformation of Drosophila with transposable element vectors. Science 218:348-353.

23. Scholnick, S. B., B. A. Morgan, and J. Hirsh. 1983. The cloned dopa decarboxylase gene is developmentally regulated when reintegrated into the Drosophila genome. Cell 34:37-45.

24. Searle, P. F., B. L. Davison, G. W. Stuart, T. M. Wilkie, G. Norstedt, and R. D. Palmiter. 1984. Regulation, linkage, and 
sequence of mouse metallothionein I and II genes. Mol. Cell. Biol. 4:1221-1230.

25. Searle, P. F., G. W. Stuart, and R. D. Palmiter. 1985. Building a metal-responsive promoter with synthetic regulatory elements. Mol. Cell. Biol. 5:1480-1489.

26. Spradling, A. C., and G. M. Rubin. 1983. The effect of chromosomal position on the expression of the Drosophila xanthine dehydrogenase gene. Cell 34:47-57.

27. Stuart, G. W., P. F. Searle, H. Y. Chen, R. L. Brinster, and R. D. Palmiter. 1984. A 12-base-pair DNA motif that is repeated several times in metallothionein gene promoters confers metal regulation to a heterologous gene. Proc. Natl. Acad. Sci. USA 81:7318-7322.

28. Stuart, G. W., P. F. Searle, and R. D. Palmiter. 1985. Identification of multiple metal regulatory elements in mouse metallothionein-I promoter by assaying synthetic sequences. Nature (London) 317:828-831.

29. Voellmy, R., and D. Rungger. 1982. Transcription of a Drosophila heat shock gene is heat-induced in Xenopus oocytes. Proc. Natl. Acad. Sci. USA 79:1776-1780. 